\title{
"BARSEENDER
}

Trascender, Contabilidad y Gestión Núm. 10 (enero - abril del 2019).

ISSN: 2448-6388. Universidad de Sonora. Departamento de Contabilidad.

Reserva de Derechos 04-2015-04172070800-203.

\section{Normatividad en el procedimiento de Auditorías de Gabinete de la Información Financiera y de Cuenta Pública para el Gobierno del Estado de Sonora}

Regulations in the procedure of Audits of the Cabinet of Financial Information and Public Account for the Government of the State of Sonora

Cecilia Ruelas Lozoya ${ }^{1}$

\section{Resumen}

El presente trabajo pretende dar a conocer el procedimiento de auditoría de gabinete al Gobierno del Estado, del Instituto Superior de Auditoría y Fiscalización (ISAF) basado en el Lineamiento de auditoría de gabinete de la información financiera trimestral y de Cuenta Pública, emitido como parte del Sistema de Gestión de Calidad de la institución, así como parte del Criterio Técnico de Evaluación y Control de la Información Financiera de los Sujetos de Fiscalización Estatales, es decir, el cómo se hace la revisión de auditoría, comentando las normas que le son aplicables, como también se describen los antecedentes de las auditorías con un breve relato de varios autores, lo que ha pasado en la historia internacional, en México y en la entidad federativa de Sonora. Es importante reconocer la historia de la auditoría, como lo mencionaron los autores, su origen fue básico e inherente ya que surgió de la necesidad de controlar, verificar y revisar los negocios, así como una forma preventiva de defraudación.

Palabras clave: auditoría de gabinete, normas, estado de Sonora.

DOI: https://doi.org/10.36791/tcg.v10i0.60

JEL: M42 Auditoría.

\section{Abstract}

The present work pretends to present the procedure of audit of cabinet to the Government of the State, of the Superior Institute of Auditing and Inspection (ISAF) based on the Audit Guideline of the quarterly financial information and Public Account, issued as part of the Quality Management System of the institution, as well as part of the Technical Criterion of Evaluation and Control of the Financial Information of the State Audit Subjects, that is, how the audit review is done, commenting on the rules that are applicable to it, The background of the audits is also described with a brief account of several authors, what has happened in international history, in Mexico and in the state of Sonora. It is important to recognize the history of the audit, as the authors mentioned, its origin was basic and inherent since it arose from the need to control, verify and review the businesses, as well as a preventive form of fraud.

Keywords: cabinet audit, standards, state of Sonora.

Recibido: 24 de noviembre de 2018.

Aceptado: 15 de febrero de 2019.

\footnotetext{
1 Cecilia Ruelas Lozoya. Contador Público. Auditor Supervisor en el Instituto Superior de Auditoría y Fiscalización. Correo: ceciliaruelas81@gmail.com
} 


\section{Introducción}

En los estudios que se han realizado sobre la auditoría, la Profesora de Ciencias Contables de la Universidad de Cienfuegos, Leidisara Martínez Calderin, hace un recorrido por la historia evolutiva de la auditoría ya que señala que la Contaduría Pública no puede ser determinada con exactitud, ya que su comienzo es el antiguo Egipto donde se fiscalizaba el empleo de materiales utilizados para la confección de tejidos. Y para algunos historiadores el registro contable tuvo su origen alrededor del año 4000 antes de Cristo, donde las civilizaciones antiguas del Cercano oriente comenzaron a establecer gobiernos y negocios organizados, procurando llevar cuentas de entradas y salidas de dinero y cobro de los impuestos, estableciendo controles para disminuir errores y fraudes, la auditoría también tiene antecedentes muy antiguos, los grandes señores se hacían acompañar de hombres de confianza al hacer negocios, préstamos, a quienes por su función de oír, se denominaron auditores, también conocido como revisor profesional; los primeros trabajos provienen de Italia en la Edad Media, en el año 1164 existían personas que ejercían esta actividad y siguiendo con la evolución a partir de 1494 se publica el desarrollo de la profesión de auditoría en todo el mundo. En el año de 1589, en Venecia se creó con carácter oficial la primera Asociación de Revisiones Profesionales. Por lo que cada país le ha dado a la auditoría la importancia que merece y su regulación por leyes, normas o decretos, evolucionando y transformándose según el desarrollo y dinámica de la actividad económica, concluye la autora. (Martínez, 2009)

Los antecedentes de la auditoría que menciona la autora Sofía A. Biler Reyes, establecen que, en el siglo XIX, por el año de 1862, aparece por primera vez la profesión de auditor o el desarrollo de la auditoría supervisada por la ley británica de Sociedades anónimas, que hasta principios del siglo $\mathrm{XX}$ seguía creciendo y extendiéndose por toda Inglaterra, llegando a los
Estados Unidos donde se fueron forjando las auditorías actuales, buscando nuevos objetivos donde la detección y la prevención del fraude pasó a segundo plano y perdía cierta importancia. Estos objetivos abarcaban las posiciones financieras de los negocios, de los socios o clientes de tal manera que se establecían los objetivos económicos en función de estos. (Biler, 2017)

\section{En México}

Los gobiernos han implementado controles para una mejor presentación en la rendición de cuentas, la calidad de los resultados de las cuentas públicas de los gobiernos es revisada por medio de auditorías y las realizan las instituciones fiscalizadoras.

Un estudio señala que la auditoría gubernamental debe coadyuvar al desarrollo de una gestión y al ejercicio adecuado del control interno y menciona una definición de auditoría:

"Un examen profesional, objetivo, independiente, sistemático, constructivo y selectivo de evidencias sobre la gestión de las entidades y personas que recaudan y manejan recursos públicos, con el objeto de determinar la razonabilidad de la información financiera y presupuestal que respalda dicha gestión y si la misma se ha realizado bajo los criterios de probidad, eficacia, eficiencia, transparencia, economía y equidad, incluyendo el grado de cumplimientos de objetivos y metas" (Muñoz, 2016)

En el libro de las Normas Profesionales de Auditoría del Sistema Nacional de Fiscalización, emitido por la institución denominada Auditoría Superior de la Federación (ASF), que es una institución que se encarga de fiscalizar el uso de los recursos públicos federales en los tres Poderes de la Unión (Ejecutivo, Legislativo y Judicial), los órganos autónomos, los estados y los municipios, e incluso los particulares cuando reciben recursos públicos, señala a la auditoría gubernamental como una actividad profesional multidisciplinaria que se ejerce por entes internos o externos en relación con el 
objeto auditado y se sujeta al cumplimiento de principios elementales comunes, se menciona que la auditoría interna juega un papel determinante para conseguir los objetivos del Sistema Nacional de Fiscalización como elemento necesario en la obtención de una mejor gestión gubernamental.

La Institución Auditoría Superior de la Federación (ASF), menciona que la auditoría es un elemento principal y necesario dentro del Sistema Nacional de Fiscalización, en el año 2014, la Secretaria de la Función Pública y las Contralorías de los estados asumieron el compromiso, dentro de sus atribuciones, de unir los elementos incluidos en las normas de auditoría con el fin de armonizar sus prácticas de acuerdo a estándares internacionales y garantizar la oportunidad y pertinencia de sus hallazgos para mejorar la gestión gubernamental.

Lográndose por medio de un proceso abierto de análisis y consulta en el seno de la Comisión Permanente de Contralores Estados-Federación, la adecuación del cuerpo normativo de las Normas Profesionales de Auditoría del Sistema Nacional de Fiscalización (NPASNF), que forman un marco de referencia en la ejecución de los entes encargados de revisar la gestión de recursos públicos, ya que determinan las líneas y directrices que establecen mejores prácticas de auditoría, asimismo en la Norma Profesional de auditoría del Sistema Nacional de Fiscalización No. 1, del nivel 1, en el apartado de Generalidades, clasifica a las auditorías según las facultades que le corresponden, en tres aspectos:

a) Auditorías financieras.

Son evaluaciones independientes, con una opinión que garantice razonablemente sobre la situación financiera de un ente, sus resultados y la utilización de los recursos apegada al marco de información financiera. b) Auditorías de cumplimiento.

Buscan determinar en qué medida el ente auditado ha observado las leyes, los reglamentos, las políticas, los códigos establecidos y otras disposiciones contractuales, comprendiendo gran variedad de materias sujetas a fiscalización.

c) Auditorías de desempeño.

Son el estudio, análisis de la economía, eficiencia y eficacia de la administración pública y los programas gubernamentales, cubren todo tipo de función gubernamental. (NPASNF, 2014)

\section{Entidad federativa: Sonora}

En la historia de la revisión de las cuentas públicas en el estado de Sonora, se puede comentar que el 15 de febrero de 1985, el Congreso del Estado de Sonora, aprobó la Ley Orgánica de la Contaduría Mayor de Hacienda, donde se crea la Contaduría Mayor de Hacienda, en el artículo 2 de esta ley se disponía:

“Artículo 2.- La Contaduría Mayor de Hacienda es el órgano técnico del Congreso del Estado, por medio del cual se revisarán anualmente la cuenta pública del Estado que deberá presentar el Ejecutivo y las cuentas públicas de los municipios que deberán presentar los ayuntamientos. Asimismo, se revisarán los estados financieros que los ayuntamientos presenten trimestralmente al Congreso del Estado.”

“Artículo 4.- La Contaduría Mayor de Hacienda, en el desempeño de sus funciones, estará bajo el control del Congreso del Estado a través de la Comisión de Vigilancia, que tendrá el carácter de permanente. Los integrantes de esta comisión serán nombrados en los términos del Decreto que Reglamenta el Funcionamiento y Gobierno Interior del Congreso del Estado de Sonora”. 
Se remite la Ley de Fiscalización Superior para el Estado de Sonora el 14 de julio de 2008 y en sus artículos Transitorios, específicamente el artículo tercero reconoce la sustitución de la Contaduría Mayor de Hacienda a Instituto Superior de Auditoría y Fiscalización, dice:

“ARTÍCULO TERCERO. - El Instituto inició sus funciones a la entrada en vigor de la Ley 81 que contiene reformas y adiciones a la Constitución Política del Estado de Sonora que lo constituyó en julio de 2005 en sustitución de la Contaduría Mayor de Hacienda, y su Titular continuará en ese cargo hasta el 31 de diciembre de 2008, según fue determinado por el Congreso del Estado al momento de su designación.”

En la misma ley expedida el 14 de julio de 2008, el artículo 6, capitulo II, señala:

“ARTÍCULO 6.- El Instituto Superior de Auditoría y Fiscalización se constituye como un órgano del Congreso del Estado dotado de autonomía presupuestaria, técnica y de gestión en el ejercicio de sus atribuciones y para decidir sobre su organización interna, funcionamiento $y$ resoluciones, en los términos que disponga la ley. Estará encargado de la revisión y fiscalización de los estados financieros y cuentas públicas estatal y municipales”.

El 17 de abril de 2017, se decreta como un organismo autónomo y en el Boletín Oficial Instituto Superior de Auditoría y Fiscalización, número 31 Secc.11, del tomo CXCIX en Hermosillo Sonora, se emite el Reglamento Interior del instituto, que en el artículo 2 dice:

"ARTICULO 2.- El Instituto, es el órgano de fiscalización superior del Estado de Sonora, que se constituye como organismo público autónomo, encargado de la revisión y fiscalización de los estados financieros y cuentas públicas estatal y municipales, fiscalizar en forma posterior los ingresos y egresos, manejo, custodia y aplicación de los recursos públicos, deuda pública, así como, las participaciones federales y también implementará acciones de prevención en materia de corrupción, en los términos establecidos por la constitución local y la ley secundaria, éste Reglamento y demás ordenamientos legales aplicables.”

Procedimiento de auditoría de gabinete según el artículo 39 de la Ley de Fiscalización Superior para el Estado de Sonora

En la Ley de Fiscalización Superior para el Estado de Sonora, en el capítulo VII, el artículo 39 describe el procedimiento, plazos y señala dos tipos de auditorías y dice:

“ARTÍCULO 39.- El Instituto deberá notificar a la entidad fiscalizada al menos con quince días hábiles de anticipación al inicio de la auditoría sea de gabinete o en el domicilio del sujeto fiscalizado, debiendo incluirse en esta notificación el año del ejercicio fiscal a auditar, así como la descripción y documentación que habrá de exhibirse ante el personal del Instituto, especificando si la auditoría será de visita domiciliaria o en sus propias instalaciones.

Apartado A: De las auditorías de gabinete..."

Partiendo del artículo 6, de la Ley de Fiscalización Superior para el Estado de Sonora, que otorga atribuciones al Instituto Superior de Auditoría y Fiscalización (ISAF) encargado de revisar y fiscalizar los estados financieros y cuentas públicas estatal y municipales, es que ha emitido un procedimiento que nombró "Lineamiento de auditoría de gabinete de la información financiera trimestral y de Cuenta Pública”, tal documento forma parte del Sistema de Gestión de Calidad del Instituto y está certificado por American 
Trust Register, S.C., al alcance de certificación: Evaluación, Revisión, Auditoría y Fiscalización de las Cuentas Públicas Estatales y Municipales en la norma (ISO 9001:2015) y estará vigente al 11 de octubre de 2019. Cabe señalar que dicho lineamiento se encuentra publicado en la página de ISAF.

\section{Objetivo de la auditoría:}

Dicho documento tiene a bien definir sus objetivos de la auditoría de gabinete en el Estado de Sonora y los clasifica como:

\section{- Objetivo}

Evaluar y controlar en base al Programa Anual de Auditoría la Información financiera trimestral y de cuenta pública anual, verificando además el cumplimiento legal de la presentación de la información contable, presupuestal, programática y anexos, con el fin de conocer la calidad de la información financiera y que se haya realizado de conformidad a lo establecido en la Ley General de Contabilidad Gubernamental.

- Objetivos específicos

Elaborar Programa Anual de auditorías de gabinete en coordinación con la Dirección General de Fiscalización al Estado y la Dirección General de Fiscalización a Municipios.

Ejecutar la evaluación y control de la información recibida por parte del Congreso del Estado y de los sujetos de fiscalización en su caso, en apego a lo dispuesto por la Ley General de Contabilidad Gubernamental y los Lineamientos emitidos por el Consejo Nacional de Armonización Contable (CONAC) y demás disposiciones normativas aplicables.

\section{A quien le aplica}

La aplicación de este lineamiento que se encuentra fundamentado en la Ley de Fiscalización Superior para el Estado de Sonora en el artículo 39, le es aplicable a cualquier organismo o persona que reciba recursos públicos, en el documento presentado por ISAF, se informa de manera muy específica a quienes le aplica la auditoría de gabinete de la información financiera trimestral y de Cuenta Pública, para cuestiones prácticas de esta lectura se nombran sujetos fiscalizados a:

“ARTÍCULO 1.- La presente ley es de orden público y tiene por objeto:

I.- Regular la revisión, auditoría y fiscalización superior de los estados financieros y cuentas públicas estatal y municipales, mediante la revisión, auditoría y fiscalización de los recursos públicos a cargo de los poderes del Estado, los ayuntamientos de los municipios del Estado, incluyendo a las entidades de la administración pública estatal y municipal, los organismos constitucional y legalmente autónomos y cualquier ente público estatal o municipal, así como cualquier persona de derecho público o privado que recaude, administre, maneje, custodie, aplique o ejerza recursos públicos;...”

\section{Fuente de información}

Es necesario para iniciar una auditoría de gabinete, contar con la información que le emana de la administración y aplicación de los recursos públicos, todos los entes públicos, deberán cumplir con presentar la información trimestral, dicha información se presenta a la Secretaria de Finanzas del Estado de Sonora, por medio de la Secretaría de Planeación del Desarrollo y Gasto Público, en la Ley del Presupuesto de Egresos y Gasto Público Estatal en el artículo 22, señala que: 
“ARTICULO 22 BIS.- La Secretaria de Planeación del Desarrollo y Gasto Público, en coordinación con la Secretaría de Finanzas, prepararán un informe trimestral de la evolución de las finanzas públicas, que incluya el comportamiento de los presupuestos de ingresos y egresos del Estado, el avance de los programas de inversión, directa y coordinada, las participaciones entregadas a los municipios y la posición de la deuda pública consolidada, así como las modificaciones que sufran los activos del patrimonio del Estado, el cual será remitido por el Ejecutivo al Congreso del Estado, dentro de los 45 días siguientes al cierre del trimestre, debiéndose publicar en el Boletín Oficial del Gobierno del Estado."

Por otro lado, para la Ley de Fiscalización Superior para el Estado de Sonora, los entes públicos están obligados a presentar la información financiera que comprenda los trimestres y todo el ejercicio fiscal, por lo que en los siguientes artículos señalan lo que se deberá cumplir:

“ARTÍCULO 7.- El Instituto revisará, anualmente, las cuentas públicas que deberán presentar los sujetos de fiscalización. Asimismo, se revisarán los estados financieros que el Estado y los ayuntamientos deberán presentar al Congreso del Estado dentro de los 45 días naturales siguientes a la conclusión del trimestre correspondiente. El Congreso del Estado deberá remitir al Instituto, dentro de las 24 horas siguientes a la fecha en que se reciban, los documentos a que se refiere este artículo. Con independencia de lo establecido en el párrafo anterior, el Instituto podrá ejercer sus facultades de fiscalización en cualquier momento, misma que se efectuará de manera independiente y autónoma de cualquier otra forma de control o fiscalización que realicen la federación y los órganos internos de control."

“ARTÍCULO 22.- La Cuenta Pública es el informe que los poderes del Estado y los entes públicos estatales presentarán de manera individual para ser consolidada a través del Ejecutivo estatal; los municipios de la Entidad y los entes públicos municipales a través de los ayuntamientos, que rinden a la legislatura local, sobre su gestión financiera a efecto de comprobar que la recaudación, administración, manejo y custodia, así como la aplicación de los recursos públicos durante el ejercicio fiscal comprendido del $1^{\circ}$ de enero al 31 de diciembre de cada año, se ejercieron en los términos de las disposiciones legales y administrativas aplicables. Una vez que sea sancionada por el Congreso tendrá el carácter de información pública, mientras ello no suceda, el Instituto deberá guardar reserva de sus actuaciones e información que proporcione. Las cuentas públicas de los poderes del Estado, de los órganos constitucional o legalmente autónomos y cualquier otro sujeto de fiscalización que reciba, administre o ejerza por cualquier motivo recursos públicos, se integrarán de manera individual, para ser presentada al Congreso del Estado de Sonora, quien lo remitirá al Instituto superior de Auditoría y Fiscalización dentro del plazo establecido en el artículo 7 de esta ley y contendrán en la medida que corresponda, de acuerdo a lo establecido por la Ley General de Contabilidad Gubernamental, lo siguiente:

I.- Información contable, con la desagregación siguiente:

II.- Información presupuestaria, 


\section{III.- Información programática,}

IV.- La información complementaria...”

\section{Procedimiento}

El lineamiento que el Instituto Superior de Auditoría y Fiscalización publicó, describe paso a paso el procedimiento de la auditoría de gabinete de la información financiera trimestral y de Cuenta Pública, que se señala en el artículo 39 de la Ley de Fiscalización Superior para el Estado de Sonora, para el tipo de auditorías, del apartado A, en el siguiente diagrama de flujo se describen las entradas, el proceso y las salidas del lineamiento. (Figura 1)

Figura 1. Descripción del Lineamiento

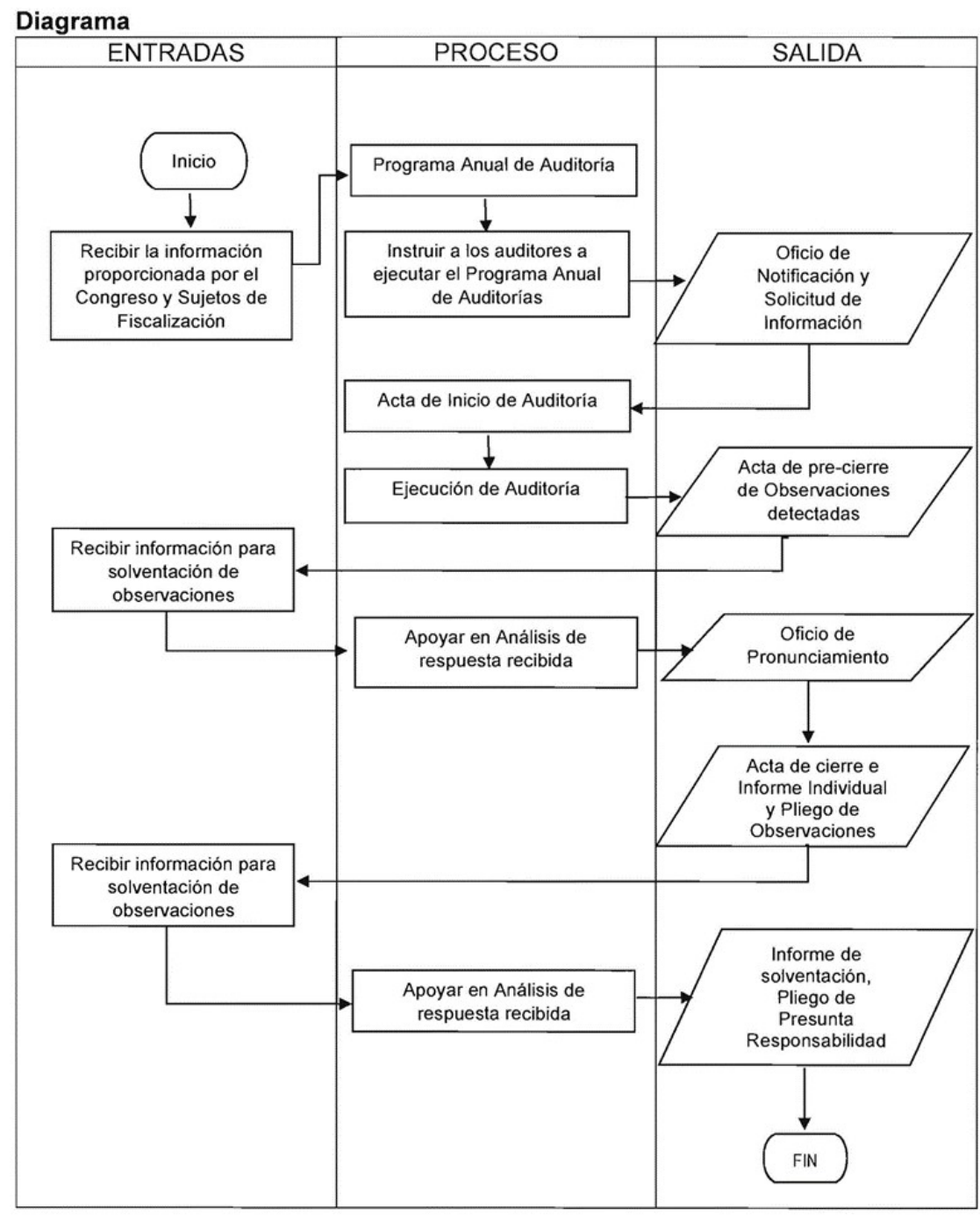

Fuente: Lineamientos de Auditoría de Gabinete de la Información Financiera Trimestral y de Cuenta Pública ISAF, 2018. 
En la Ley de Fiscalización Superior para el Estado de Sonora en el artículo 17 dice:

“ARTÍCULO 17.- El Instituto, además de las atribuciones específicas establecidas por la Constitución Política del Estado de Sonora, tendrá las siguientes:

I.- Definir y establecer los lineamientos, criterios, procedimientos, métodos y sistemas necesarios para la realización de las funciones de auditoría y fiscalización de las cuentas públicas y de los estados financieros y deuda pública, tomando en consideración las disposiciones legales aplicables;"

Con la atribución que el artículo anterior establece para ISAF, crea el "Lineamiento de auditoría de gabinete de la información financiera trimestral y de Cuenta Pública” que es aplicable tanto para las revisiones de los organismos estatales y municipales, en este trabajo se enfocará a las auditorías de gabinete al Gobierno del Estado, ósea, las estatales, que se componen de organismos autónomos, dependencias y entidades paraestatales, actualmente el lineamiento se encuentra a cargo de la Dirección de Evaluación y Control de Fiscalización al Gobierno del Estado de Sonora, a continuación, se describe el procedimiento que se ha clasificado en tres etapas:

\section{Planeación y actividades previas a la Ejecución de la auditoría:}

En esta etapa se planea la revisión de las auditorías, basándose en el Programa Anual de Auditorías de la institución y se realiza el programa de revisión de las auditorías a los sujetos fiscalizados del Gobierno del Estado, tomando en cuenta los puntos siguientes:

a) Se recibe la información proporcionada por el Congreso del Estado a ISAF por medios magnéticos e impreso, conforme al artículo 7 de b) la Ley de Fiscalización Superior para el Estado de Sonora antes señalado.

c) Se elabora el Programa Anual de Auditorías de Gabinete de los Informes Financieros y de Cuenta Pública, la cual se adiciona al Programa Anual de Auditorías de ISAF, se toma en cuenta el programa del año inmediato anterior y la documentación que envían los Poderes del Gobierno del Estado.

En reunión con la Dirección de Evaluación y Control de Fiscalización y los auditores supervisores se da a conocer el programa de auditorías, se entregan las tareas según con los recursos que se dispongan y las cargas de trabajo vigente, además de los tiempos asignados para entregar el trabajo final.

2. Ejecución del Programa Anual de Auditoría con respecto a las Auditorías de Gabinete de los Informes Financieros Trimestrales y de Cuenta Pública.

En esta etapa se registran los sujetos a fiscalizar del Programa Anual de Auditorías, en el Sistema de Gestión de Auditoría y Seguimiento a cargo de la Dirección General de Tecnologías de la Información de ISAF, asignándoles un número con el cual quedan registrados, cabe señalar que en reunión con la Dirección de Evaluación y Control de Fiscalización se asignan las auditorías a cada uno de los auditores supervisores, quienes se hacen cargo de:

d) Elaborar el oficio de Notificación de la auditoría por medio del sistema y se notifica al sujeto de fiscalización de acuerdo a la programación anual de auditorías.

e) $\mathrm{Si}$ es necesario se solicita a los sujetos de fiscalización información adicional, para realizar la auditoría de gabinete a los informes trimestrales y de cuenta pública. 
f) Se elabora acta de inicio, utilizando el sistema.

g) Se ejecuta la revisión según lo que establece el Criterio Técnico de Evaluación y Control de la información financiera de los sujetos fiscalizados, que detalla las actividades necesarias para llevar a cabo la auditoría, de tal revisión resultan las observaciones detectadas de pre-cierre.

h) Se revisa por parte de la Dirección de Evaluación y Control de Fiscalización, las observaciones detectadas de pre-cierre.

i) Se elabora y entrega el acta de pre-cierre de observaciones detectadas al sujeto fiscalizado.

j) Se recibe y analiza la información que entrega el sujeto fiscalizado para resolver las observaciones y recomendaciones de pre-cierre.

k) Se elabora el oficio de Pronunciamiento y se notifica al sujeto fiscalizado sobre la procedencia de las resoluciones presentadas en la etapa de pre-cierre.

l) Se elabora el acta de cierre de auditoría, utilizando el sistema.

\section{Elaboración del Informe Individual de Auditoría}

Con el acta de cierre queda concluida la etapa de ejecución, así como la auditoría, por lo que corresponde a elaborar el informe individual de auditoría, documento que se emite para dictaminar los resultados de la revisión elaborada y según la Ley de Fiscalización Superior para el Estado de Sonora, debe contener:

“ARTÍCULO 47.- Los Informes Individuales de auditoría contendrán como mínimo lo siguiente:

I.- Los criterios de selección, el objetivo, el alcance, los procedimientos de auditoría aplicados y el dictamen de la revisión;
II.- Los nombres de los servidores públicos del Instituto Superior de Auditoría y Fiscalización a cargo de realizar la auditoría o, en su caso, de los despachos o profesionales independientes contratados para llevarla a cabo;

III.- El cumplimiento, en su caso, de la Ley de Ingresos, el Decreto del Presupuesto de Egresos, de la Ley Federal de Deuda Pública, la Ley de Coordinación Fiscal, de la Ley General de Contabilidad Gubernamental, y demás disposiciones jurídicas;

IV.- Los resultados de la fiscalización efectuada;

V.- Las observaciones, recomendaciones, acciones, con excepción de los informes de presunta responsabilidad administrativa y, en su caso, denuncias de hechos; $y$

VI.- Un apartado específico en cada una de las auditorías realizadas donde se incluyan una síntesis de las justificaciones y aclaraciones que, en su caso, las entidades fiscalizadas hayan presentado en relación con los resultados y las observaciones que se les hayan hecho durante las revisiones...Los informes individuales a que hace referencia el presente capítulo tendrán el carácter de públicos, y se mantendrán en la página de Internet del Instituto Superior de Auditoría y Fiscalización, en formatos abiertos."

Los pasos que el lineamiento para la auditoría de gabinete señala para el informe individual de auditoría son:

m) Se elabora el informe individual de auditoría y el Pliego de observaciones, en su caso, mediante la ayuda del sistema, el pliego es el documento que 
incluye los resultados finales de las observaciones que no se solventaron.

n) Se remite el pliego de observaciones a la Dirección General de Asuntos Jurídicos para validar la Normatividad infringida.

o) Se entrega el informe al Auditor Adjunto, al Director General de Asuntos Jurídicos y al Auditor Mayor para su autorización y posterior notificación al sujeto fiscalizado.

p) Se recibe y analiza la información entregada por el sujeto fiscalizado para resolver las observaciones y recomendaciones que quedaron pendientes de solventar, utilizando el sistema.

q) Se elabora un documento denominado informe de solventación mediante el sistema informático, se envía al Director General de Asuntos Jurídicos y al Auditor Mayor para la autorización y posterior notificación al sujeto fiscalizado.

r) Se elabora el Pliego de Presunta Responsabilidad de las observaciones que no hayan sido solventadas en el plazo de 30 días hábiles, citados en el informe individual y se turna a la Dirección General de Investigación del Instituto, para que proceda como corresponda.

Cabe señalar que, en la segunda etapa de la ejecución del Programa Anual de Auditoría, se hace mención a el Criterio Técnico de Evaluación y Control y se refiere a la descripción de actividades para realizar la auditoría de gabinete a la información financiera trimestral y de cuenta pública, para su revisión se clasificó en cuatro apartados que contienen la información contable, presupuestal, programática y complementaria y anexos, de manera general se describe la información que se revisa, verifica, compara y analiza de cada una:
1. Información Contable

Se revisa la información contable que se compone de los siguientes estados e información contable: Estado de Situación Financiera, Estado de Actividades, Estado de Variación en la Hacienda Pública, Estado de Cambios en la Situación Financiera, Estado de Flujo de Efectivo, Estado Analítico del Activo, Estado Analítico de la Deuda y Otros Pasivos, Informe sobre pasivos contingentes y Notas a los Estados Financieros.

2. Información Presupuestal

Se revisa la información presupuestaria que se compone de los estados e informes siguientes: Estado Analítico de Ingresos, Conciliación entre los ingresos presupuestales y los contables, Estado Analítico del Ejercicio del Presupuesto de Egresos, Conciliación entre los Egresos presupuestales y los contables, Endeudamiento Neto e Intereses de la Deuda.

3. Información Programática

Se revisa la información programática, los siguientes estados e informes lo componen: Gasto por Categoría Programática, Gasto por Proyectos de Inversión, Informe de Avance Programático y Matriz de Indicadores de Resultados.

4. Información Complementaria y Anexos

Se revisa la información complementaria y anexos que está integrada por: los Indicadores de Postura Fiscal, Relación de Cuentas Bancarias productivas específicas, Relación de Bienes que componen el patrimonio y Análisis de Variaciones Programático-Presupuestal. 
La información antes descrita se evalúa y controla, también se verifica el cumplimiento legal de la presentación de la información contable, presupuestaria, programática, complementaria y anexos, con el propósito de conocer la calidad de la información financiera, que se haya emitido conforme a los ordenamientos correspondientes relacionados a la Ley General de Contabilidad Gubernamental y los acuerdos del Consejo Nacional de Armonización Contable.

Los informes individuales de auditoría, una vez notificados a los sujetos fiscalizados, son publicados en la página: https://isaf.gob.mx/, en la sección Transparencia, en Obligaciones Estatales artículo 83 BIS, fracción V, de la Ley de Transparencia y Acceso a la Información Pública del Estado de Sonora que dispone:

“Artículo 83 Bis. - Además de lo dispuesto en el artículo 81 de esta Ley, los Órganos Fiscalizadores de los tres poderes en el Estado, incluyendo los Órganos Internos de Control y Evaluación Gubernamental de cada municipio y el Instituto Superior de Auditoría y Fiscalización, así como, los auditores externos, deberán poner a disposición del público mantener actualizada, en términos de lo establecido en el presente Capitulo, la siguiente información:

\section{V.- Informes Individuales de Auditoría.”}

En la Ley de Fiscalización Superior para el Estado de Sonora, en sus artículos 46 y 47 se emite la obligación de que los informes individuales deberán ser entregados a más tardar el día 30 de agosto del año de la presentación de la Cuenta Pública y que el ISAF dará cuenta de las observaciones, recomendaciones y acciones, de multas y todas las acciones que resulten de las auditorías realizadas.

\section{Normatividad aplicada al procedimiento de auditoría de gabinete}

La normatividad no puede estar ausente en las auditorías, es la herramienta indispensable para saber qué hacer, como hacerlo y porque se debe hacer, Ley de Fiscalización establece que las revisiones y fiscalizaciones de las cuentas públicas, se deberán tener en cuenta toda la normativa que le aplique. En la figura aparecen algunas de las normas aplicables. (Figura 2)

“ARTÍCULO 23.- En el ejercicio de la función de auditoría, revisión y fiscalización de las cuentas públicas por parte del Instituto, se tendrán en cuenta las siguientes consideraciones:

II.- En los procedimientos de fiscalización se utilizarán las Normas de Auditoría Generalmente Aceptadas, las Normas de Información Financiera emitidas por el Instituto Mexicano de Contadores Públicos, los Postulados Básicos de Contabilidad Gubernamental, Normas Profesionales del Sistema Nacional de Fiscalización, las mejores prácticas y toda aquella disposición normativa aplicable en la materia" (Ley de Fiscalización Superior para el Estado de Sonora, 2017) 
Figura 2. Principales Normas utilizadas en Auditoría de Gabinete.

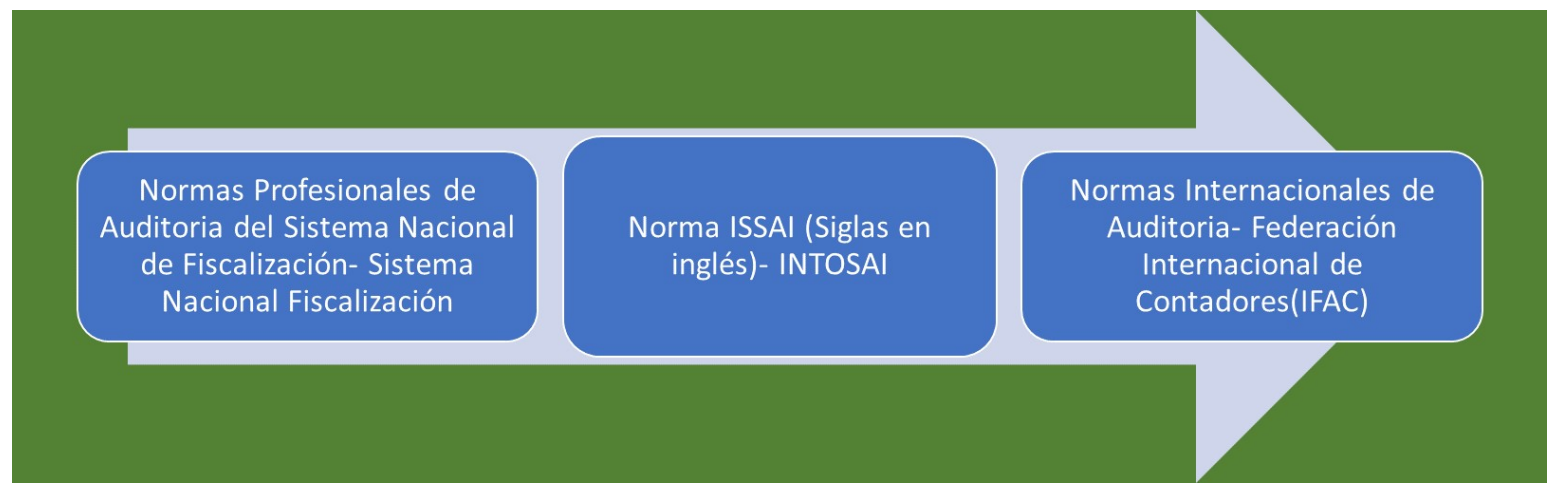

Fuente: Elaboración propia.

La norma básica ISSAI 100 "Principios Fundamentales de Auditoría del Sector Público" esta norma presenta de manera detallada el propósito y autoridad de las ISSAIs, el marco de referencia y los elementos para la auditoría del sector público y los principios que deben aplicarse en la auditoría del sector público, en la siguiente figura se observan las áreas que cubren los principios fundamentales de auditoría del sector público:

Figura 3. Principios Fundamentales de auditoría del Sector Público.

\section{Áreas cubiertas por los principios de la auditoria del sector público}
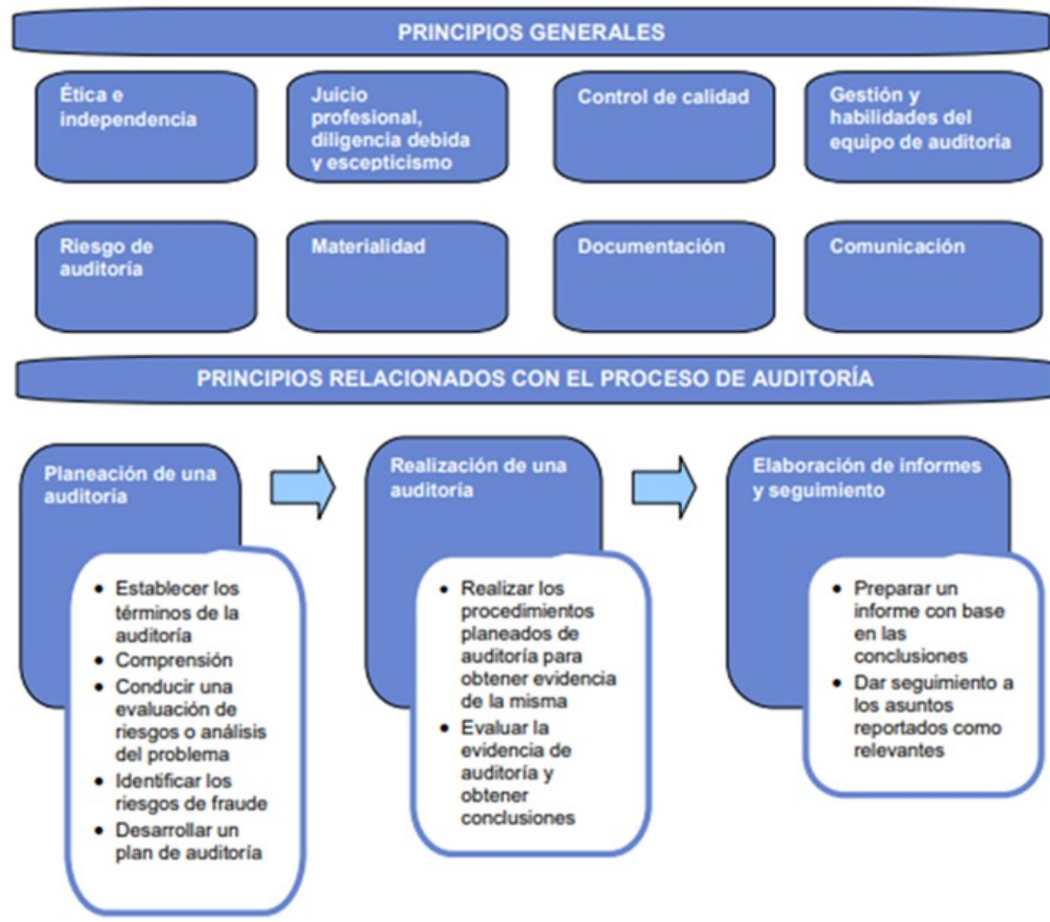

Fuente: ISSAI 100 Principios Fundamentales de Auditoría del Sector Público INTOSAI (2009). 
La norma ISSAI 200 Principios Fundamentales de la Auditoría Financiera, proporciona las herramientas para una auditoría de estados financieros, así como información detallada sobre: el propósito y autoridad de los Principios Fundamentales de la Auditoría Financiera, el marco de referencia para auditar estados financieros en el sector público, los elementos y los principios de una auditoría de estados financieros.

Las Normas Profesionales de Auditoría del Sistema Nacional de Fiscalización (NPASNF) constituyen un marco de referencia para la actuación de aquellos entes encargados de revisar la gestión de los recursos públicos, y señalan líneas y directrices que constituyen las mejores prácticas en la materia:

La NPASNF 100 - Principios Fundamentales de Auditoría del Sector Público proporciona los principios fundamentales para la auditoría del sector público en general, y define la autoridad y alcance de las NPASNF.

La NPASNF 200 - Principios Fundamentales de la Auditoría Financiera, ha sido adaptada para abordar los aspectos clave relacionados con una auditoría de estados financieros en el sector público. Amplía y desarrolla aún más los principios fundamentales de la NPASNF100 para ajustarse al contexto específico de las auditorías de estados financieros, y constituye la base para las normas de auditoría de los estados financieros. La NPASNF200 se debe leer $y$ comprender en conjunto con la NPASNF 100. (NPASNF, 2014)

Con relación a la revisión, al planear la auditoría se toma en cuenta la materialidad para ejecutarla, se refiere a la importancia relativa a las cifras a determinar por el auditor en los informes individuales que se realizan en
ISAF para las auditorías de gabinete, la Norma aplicada para la materialidad es la ISSAI 1320 "La materialidad al planificar y ejecutar una auditoría”

En la nota práctica menciona que orienta a los auditores del sector público sobre la NIA $320 \mathrm{La}$ materialidad al planificar y ejecutar una auditoría, que establece:

La NIA 320 establece la obligación para el auditor de aplicar el concepto de materialidad o importancia relativa en la planificación y en la ejecución de una auditoría de los estados financieros. La NIA 4502 explica el modo en que se aplica este concepto al evaluar el efecto de las incorrecciones detectadas en la auditoría y de las no corregidas, en su caso, en los estados financieros. (INTOSAI, 2009)

\section{Conclusiones}

El presente trabajo mencionó una parte de la historia de la auditoría, se dieron a conocer los comentarios de varios autores.

Se plasmó el diagrama de flujo del Lineamientos de Auditoría de Gabinete de la Información Financiera Trimestral y de Cuenta Pública y se desarrolló por etapas y cada uno de los puntos que las contenían, siguiendo el ordenamiento que marca la Ley de Fiscalización Superior para el Estado de Sonora en el artículo 39.

Se mencionaron algunas normas que aplican a la auditoría de gabinete y se presentaron gráficamente.

El lineamiento que se nombró en el presente trabajo podría estar sujeto a cambios por la Ley de Fiscalización Superior para el Estado de Sonora, pero las normas estarían vigentes para aplicarlas en las revisiones de las auditorías. 


\section{Referencias:}

Martínez Calderin Leidisara. (2009). El control interno: Un medio eficaz para la toma de decisiones en el control de la gestión. Bibliociencias, 19, 71. Recuperado de http://www.bibliociencias.cu/gsdl/collect/revistas/index /assoc/HASH6e54/32a38a83.dir/doc.pdf

Muñoz, V. A. S. (2016). La auditoría gubernamental y su incidencia en el desarrollo de La gestión en La municipalidad distrital de nuevo chimbote, 2016.

Biler-Reyes Sofía A (2017). Auditoria. Elementos esenciales Audit. Essential elements Auditoria. elementos essenciais. 3, 138-151. Recuperado de https://dialnet.unirioja.es/descarga/articulo/5907383.pd $\mathrm{f}$

Congreso del Estado de Sonora. (sin fecha). Ley de Fiscalización Superior para el Estado de Sonora. 1$48 . \quad$ Recuperado de http://www.congresoson.gob.mx:81/Content/Doc_leye s/doc_432.pdf

ASF. (2014). Normas Profesionales de Auditoría del Sistema Nacional de Fiscalización. (3 septiembre). Recuperado de https://www.asf.gob.mx/uploads/61_Publicaciones_tec nicas/NormasProfesionales2014.pdf

Congreso del Estado de Sonora. (2008). Ley de Fiscalización Superior para el Estado de Sonora, pp. 1-48. Recuperado de http://www.congresoson.gob.mx:81/Content/Doc_leye s/doc_432.pdf
Congreso del Estado de Sonora. (sin fecha). 18 sección I, Boletín Oficial Contaduría Mayor Hacienda. Recuperado de http://www.boletinoficial.sonora.gob.mx/boletin/i mages/boletinesPdf/2005/julio/2005CLXXVI3III. pdf

ISAF 2018. (2018). Lineamientos de Auditoría de Gabinete de la Información Financiera Trimestral. Recuperado de https://intranet.isaf.gob.mx/Publico/Calidad/26

Congreso del Estado de Sonora. (2014). Ley del Presupuesto de Egresos y Gasto Público Estatal, pp. 1-19. Recuperado de https://intranet.isaf.gob.mx/Publico/Documento/181

INTOSAI. (2013). ISSAI 100 Principios Fundamentales de Auditoría del Sector Público, pp. 1-18.

INTOSAI. (2013). ISSAI 200 Principios Fundamentales de la Auditoría Financiera, pp. 1-46.

INTOSAI. (2009). ISSAI 1320 La materialidad al planificar y ejecutar una auditoría.

H. Congreso del Estado de Sonora. (2016). Ley De Transparencia, Acceso a La Información Pública $Y$ Protección De Datos Personales Para El Estado De Sonora, pp. 1-25. Recuperado de https://intranet.isaf.gob.mx/Publico/Documento/160 